\title{
Oxidation and corrosion behaviour of laser-alloyed mild steel with chromium
}

\author{
A K PATTANAIK, A S KHANNA, C S HARANDRANATH*, \\ $\mathrm{K}$ WISSENBACH ${ }^{\dagger}$ and G L GOSWAMI ${ }^{\dagger \dagger}$ \\ Corrosion Science and Engineering Programme, ${ }^{*}$ RSIC, Indian Institute of Technology, \\ Bombay 400076 , India \\ ${ }^{\dagger}$ Fraunhofer Institute for Lasertechnik, Aachen, Germany \\ "Bhabha Atomic Research Centre, Bombay 400085, India \\ MS received 20 October 1994; revised 22 February 1995

\begin{abstract}
The oxidation and corrosion of mild steel coated with chromium powder followed by laser treatment has been investigated. Chromium powder was deposited on mild steel surface using atmospheric plasma spraying. The chromium-coated surface was irradiated separately using a pulsed $\mathrm{Nd}$ :YAG laser and a continuous $\mathrm{CO}_{2}$ laser. The oxidation tests were carried out in air at $700^{\circ} \mathrm{C}$ and anodic polarization tests in $1 \mathrm{~N} \mathrm{H}_{2} \mathrm{SO}_{4}$ solution. There was significant difference in the morphologies of the sarface alloys formed using $\mathrm{CO}_{2}$ laser and Nd:YAG laser. Samples treated with $\mathrm{CO}_{2}$ laser showed better oxidation resistance whereas the surface alloys formed using Nd:YAG laser showed poor oxidation resistance. Anodic polarization tests carried out on samples laser-treated with $\mathrm{CO}_{2}$ laser showed improved corrosion resistance.
\end{abstract}

Keywords. Oxidation; corrosion; laser treatment; surface alloying; plasma coating; chromium coating.

\section{Introduction}

Mild steel is generally used for many low- and moderate-temperature applications. However, its applications are restricted because of its inherently poor resistance to moisture, oxygen and other gases present in the atmosphere. It reacts quickly and accumulates heavy corrosion products when exposed to atmosphere. Protective coatings, inorganic or organic, and paints are generally employed when such steels are used in aggressive environments such as marine, acidic or strong basic (Macdowell 1992). These methods are, however, temporary and need replenishment of paint coatings quite often. Thus, an alternative method of improving mild steel and other low-alloy steels is by forming a corrosion-resistant surface alloy, which permanently protects the steel from corrosion not only at ambient temperatures but also at higher temperatures. This can be achieved by altering the surface composition, favouring the formation of passive film at ambient temperatures or protective oxide layer at higher temperatures.

Methods such as electroplating (Honey et al 1986), spray coatings (Parks 1985; Arvidsson 1992) and plasma coatings (Lugscheider et al 1985; Fairbanks and Hecht 1987) have been in use for a long time to deposit protective materials on the surface of mild steels or other less-corrosion-resistant materials. Plasma spray techniques have inherent advantages over other spray techniques because of their higher density, homogeneity, etc. However, the main limitations of these techniques are their rough and porous surface and poor bonding to the substrate. Such overlay coatings can be improved further if they are remelted. 
The use of lasers for surface modification such as surface melting/alloying, surface hardening, and surface cladding of metals has now become a well-accepted material processing technique (Gasser et al 1988; Steen and Watkins 1993). A number of studies have been carried out which highlight the use of laser to improve the oxidation and corrosion behaviour of metals and alloys (Chiba et al 1984; Stott et al 1987; Roy et al 1993). Laser surface alloying provides a unique facility where surface alloys can be made with ease, cleanliness and at a much faster rate. This is achieved because of high delivery rate of energy and localized surface melting of the pre-deposited alloying elements (or a simultaneous feed of powder of desired element) and a portion of the substrate, without affecting the bulk properties of the materials.

In the present work, an attempt has been made to study the influence of laser treatment on the oxidation and corrosion behaviour of chromium-coated mild steel. Similar work on stainless steel, plasma coated on mild steel, followed by laser treatment, showed considerable improvement in oxidation behaviour (Khanna et al 1992). Improved corrosion resistance of electrodeposited chromium on $9 \mathrm{Cr}-1 \mathrm{Mo}$ steel followed by laser treatment has been observed (Pujar et al 1993).

\section{Experimental}

\subsection{Plasma coating of chromium on mild steel}

Mild steel samples $(100 \mathrm{~mm} \times 50 \mathrm{~mm} \times 2 \mathrm{~mm})$ were degreased and then sand-blasted (surface finish of SA $2 \frac{1}{2}$ as per Swedish specification) before plasma coating. A $60 \mu \mathrm{m}$ thick coating of chromium was obtained using atmospheric plasma technique, at Laser and Plasma Division, BARC, Bombay. The following plasma parameters were used for this purpose:

Plasma torch power: $20 \mathrm{~kW}$

Plasma gas: $201 / \mathrm{min}$ argon $+11 / \mathrm{min}_{2}$

Current: 350 amp

Voltage: $25 \mathrm{~V}$

Powder feed rate: $15 \mathrm{~g} / \mathrm{min}$

Power carrier gas: $81 / \mathrm{min}$ argon

Specimen to torch distance: $125 \mathrm{~mm}$.

\subsection{Laser irradiation}

Laser irradiation was carried out on the coated specimens. A $300 \mathrm{~W}$ Nd:YAG pulse laser and a $3 \mathrm{~kW}$ continuous $\mathrm{CO}_{2}$ laser were used for this purpose. Laser irradiation using a $300 \mathrm{~W}$ Nd:YAG laser was carried out at BARC. A focused laser beam of energy 4 to $8 \mathrm{~J}$ with pulse width varying from 8 to $12 \mathrm{~ms}$ was used for laser alloying with power frequency of $8 \mathrm{~Hz}$, under argon flow, at the rate of $0.5 \mathrm{~kg} / \mathrm{cm}^{2}$. The sweep speed was maintained at $2 \mathrm{~mm} / \mathrm{sec}$. Six different tracks were obtained by varying the laser processing parameters, shown in table 1. Samples treated using Nd:YAG laser with different pulse energies and pulse width are designated LT1 to LT6 as given in table 1.

Laser treatment using a $5 \mathrm{~kW}$ continuous $\mathrm{CO}_{2}$ laser was carried out at Fraunhofer Institute for Laser Technique, Aachen, Germany. A $3 \mathrm{~kW}$ laser beam in line focus 


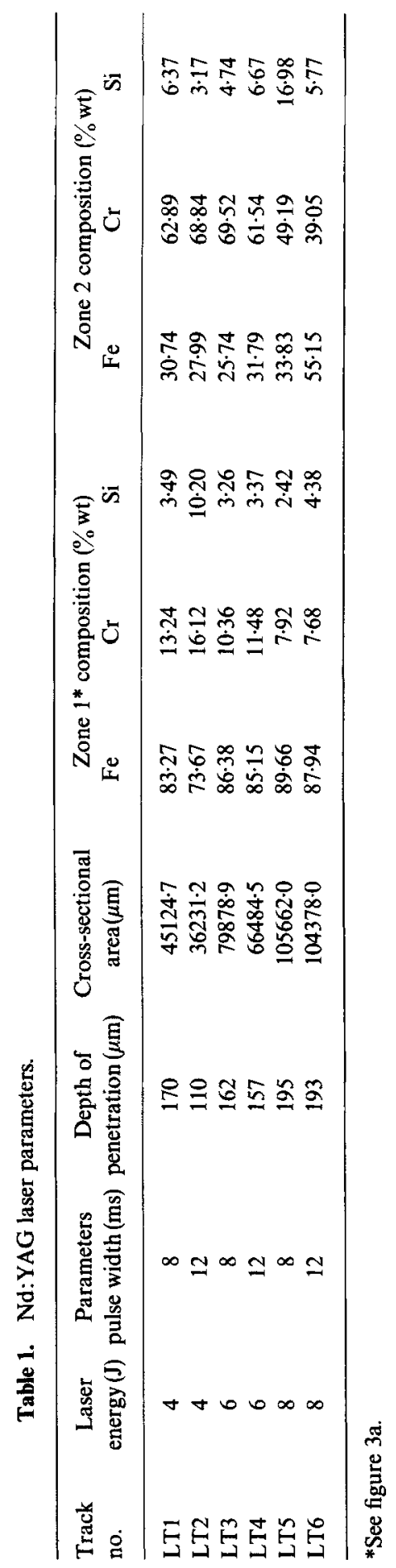


Table 2. $\mathrm{CO}_{2}$ laser parameters.

\begin{tabular}{lccl}
\hline Sample no. & $\begin{array}{c}\text { Sweep speed } \\
(\mathrm{mm} / \mathrm{min})\end{array}$ & $\begin{array}{c}\text { Interaction } \\
\text { time }(\mathrm{ms})\end{array}$ & $\begin{array}{l}\text { Thickness of } \\
\text { laser-melted } \\
\text { zone }(\mu \mathrm{m})\end{array}$ \\
\hline LT9 & 500 & 60 & 275 \\
LT8 & 625 & 48 & 250 \\
LT7 & 750 & 40 & 200 \\
\hline
\end{tabular}

mode (spot size $0.5 \mathrm{~mm} \times 6 \mathrm{~mm}$ ) was used for irradiation, which gave an energy density of 105 watts $/ \mathrm{cm}^{2}$. Irradiation was carried out under a continuous Ar flow at the rate of $20 \mathrm{l} / \mathrm{min}$. The sweep speed was varied from 750 to $500 \mathrm{~mm} / \mathrm{min}$, which gave an interaction time of 40 to $60 \mathrm{~ms}$. Samples treated using $\mathrm{CO}_{2}$ laser with three sweep speeds are designated LT7 to LT9 (table 2).

\subsection{Microstructural analysis}

The coated and laser-treated samples were mounted in epoxy for the cross-sectional analysis. The mounted specimens were polished to fine diamond finish, cleaned in acetone and chemically etched in $3 \%$ nital solution to reveal the microstructure. Concentration of the alloying elements in the melted zone was determined by the line scan mode using electron probe microanalysis. The surface morphologies of the plasma-coated and the laser alloyed specimens were observed in a scanning electron microscope.

\subsection{Oxidation studies}

The oxidation tests were carried out in air at $700^{\circ} \mathrm{C}$ for $100 \mathrm{~h}$ by exposing the uncoated, plasma-coated and laser-treated specimens. The change in weight was measured after a definite interval of time by interrupting the experiment.

\subsection{Corrosion studies}

The corrosion behaviour of the samples laser-treated using $\mathrm{CO}_{2}$ laser was investigated in $1 \mathrm{~N}_{2} \mathrm{SO}_{4}$ solution using potentiodynamic polarization technique. The laseralloyed specimen of size $1 \mathrm{~cm}^{2}$ was used for this purpose. The sample was mounted in epoxy resin with an electric contact on the reverse side using a copper wire. Anodic polarization experiments were carried out by measuring the electrode potentials with respect to a saturated calomel electrode (SCE) and were started from a cathodic potential of $-700 \mathrm{mV}$ (SCE) and continued until transpassivity was obtained, with a scan rate of $1 \mathrm{mV} / \mathrm{sec}$. Subsequent polarization tests were carried out on the same sample after repolishing the sample approximately up to $40 \mu \mathrm{m}$ each time with a 600 grit $\mathrm{SiC}$ paper until the mild steel reappeared. Anodic polarization curves thus obtained were analysed for corrosion potential, corrosion current density, critical current density, passive current density and passive potential range. 


\section{Results}

\subsection{Characterization of plasma and laser treated samples}

3.1a Plasma-coated specimen: The surface morphology of the plasma-coated sample is shown in figures $1 \mathrm{a}$ and $1 \mathrm{~b}$. It is clear from these figures that the coating is uneven and has many pores. The cross-section of the coated sample, observed using an optical
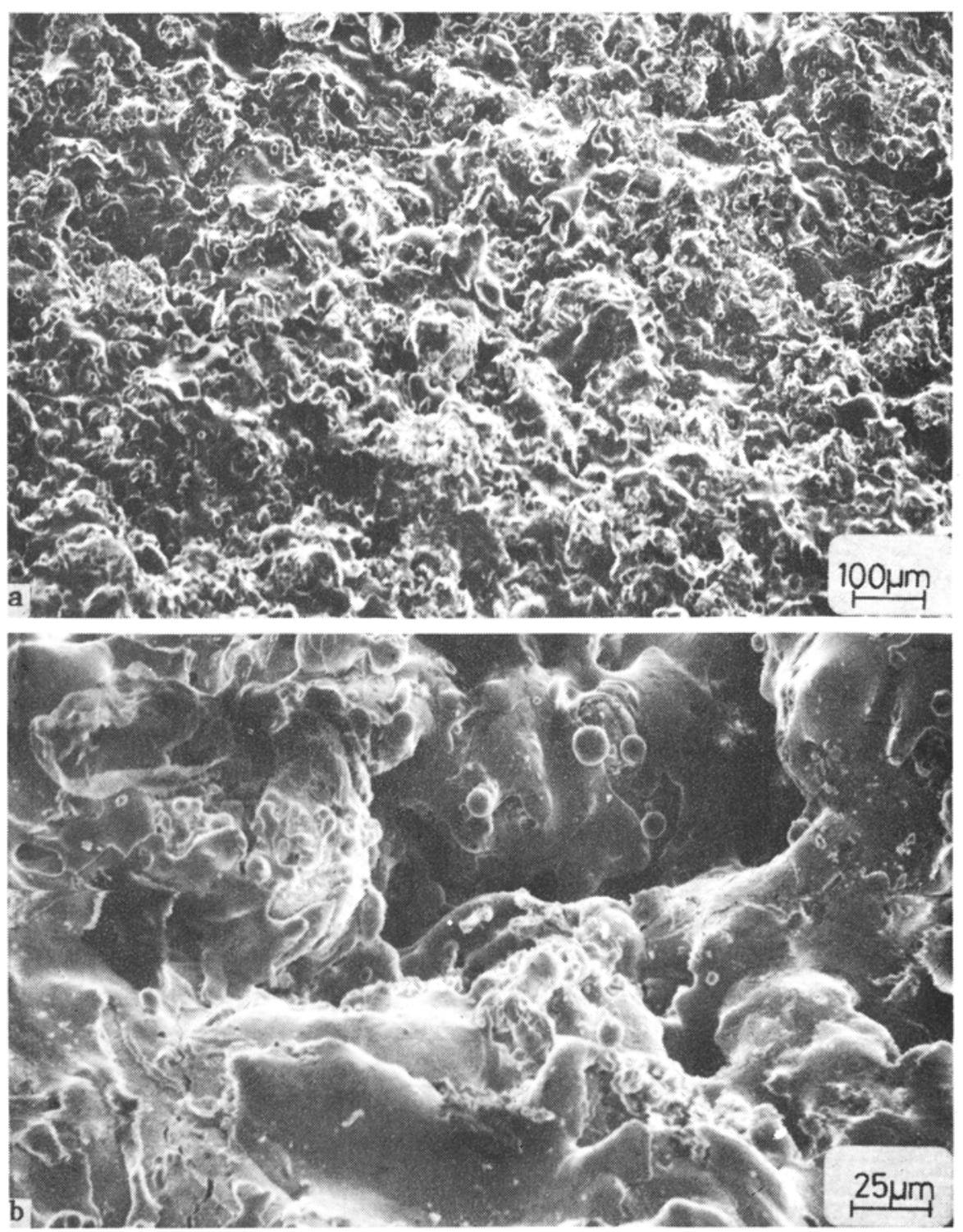

Figure 1. SEM micrographs showing (a) the surface morphology of the chromium plasmacoated on mild steel and (b) the same at higher magnification showing pores. 
microscope, also reveals the porous and uneven nature of the coating, as shown in figure 2. The thickness of the $\mathrm{Cr}$ coating is found to be $60 \mu \mathrm{m}$.

3.1b Nd:YAG laser-treated specimen: Figure 3a shows the surface morphology of the Nd:YAG laser-treated specimen. Each track shows two different zones (with $60 \%$ overlapping), which are magnified and shown in figures $3 \mathrm{~b}, 3 \mathrm{c}$ and $3 \mathrm{~d}$. Figure $3 b$ reveals zone-1 (Z-1) as a dense and uniform coating whereas figures $3 \mathrm{c}$ and $3 \mathrm{~d}$, of zone-2 (Z-2), show chromium oxide particles, which might have formed as a result of the oxidation of chromium during laser treatment. Figure $3 \mathrm{c}$ also shows a crack in Z-2 along with chromium oxide particles. The compositions of the two zones, analysed by EDAX, are summarized in table 1 . The weight percentage of chromium was found to be more in Z-2 than in Z-1. The effect of energy and pulse width on the chromium in the laser-alloyed zone for various tracks is illustrated in figure 4 . It shows that at constant energy and with varying pulse width the chromium concentration in the two zones increases. But with varying

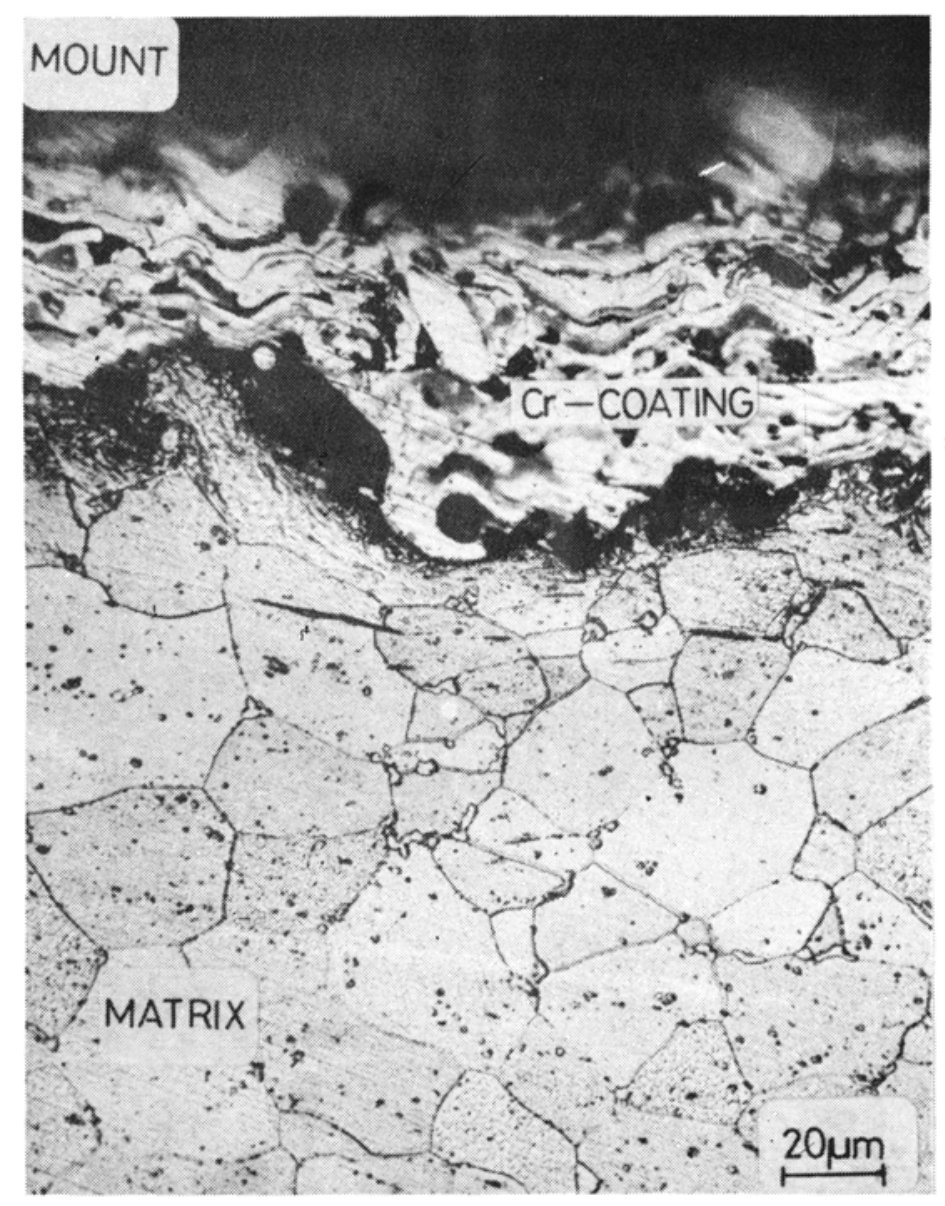

Figure 2. Optical micrograph showing the cross-section of the chromium coating plasmacoated on mild steel. 
energy and at constant pulse width the chromium concentration decreases as shown in figure 5 .

Typical optical micrographs of the cross-section of the samples made using laser parameters LT2 and LT5 along with X-ray line scan analysis are shown in figure 6. The depth of penetration and the area of laser-alloyed zones calculated for each track with different laser parameters, viz. pulse energy and width, using an image analyser, are listed in table 1.

3.1c $\mathrm{CO}_{2}$ laser-treated specimen: The surface morphology of the $\mathrm{CO}_{2}$ laser-treated specimen is given in figures $7 \mathrm{a}$ and $7 \mathrm{~b}$. A uniform and dense surface is clearly evident from figure 7a. Analysis of the surface indicated that a large triangular phase rich in chromium, probably chromium oxide, and a round iron-rich phase (figure $7 \mathrm{~b}$ ) formed during laser processing. There was not much difference in the surface
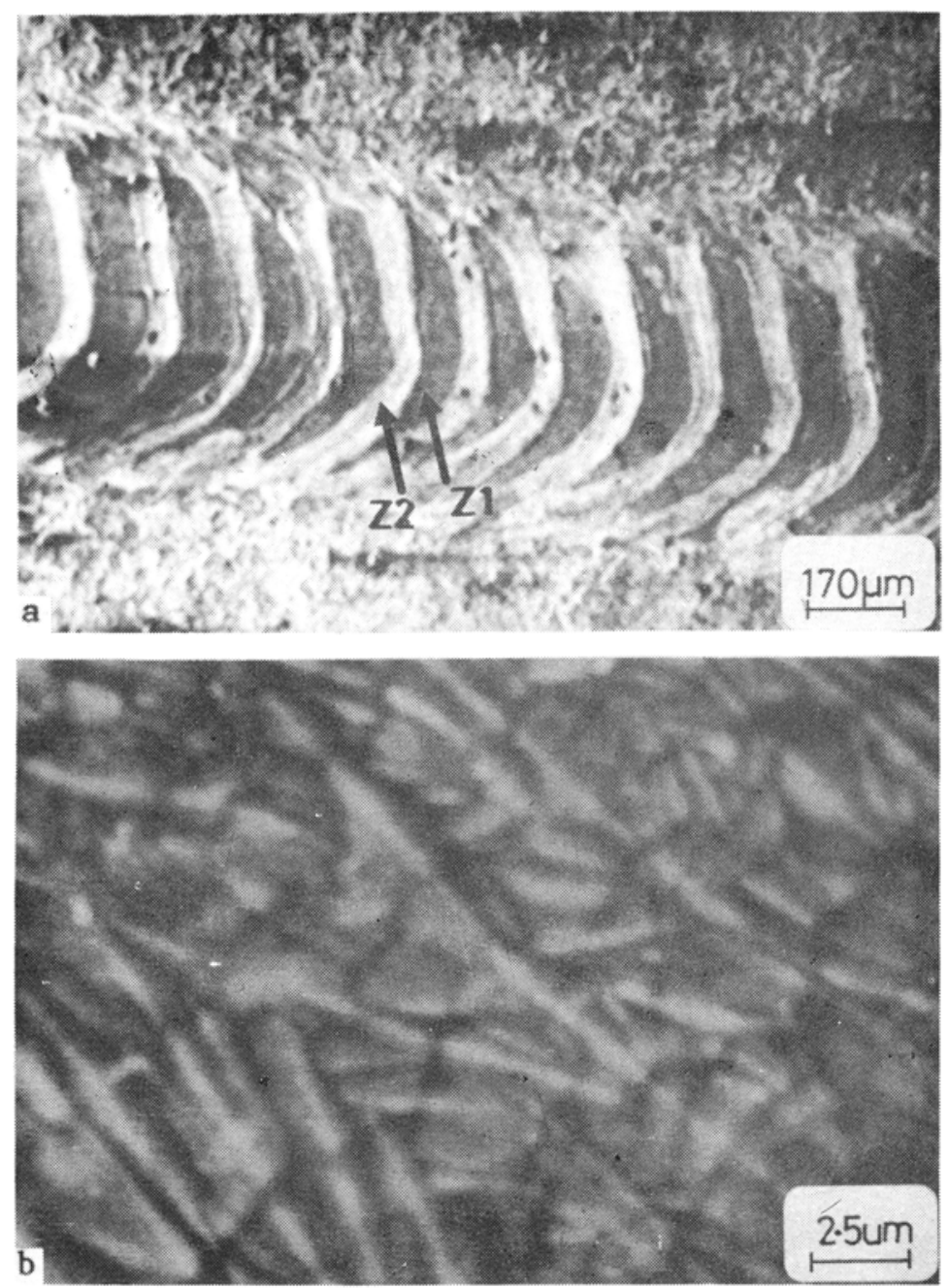

Figure 3. a-b. 

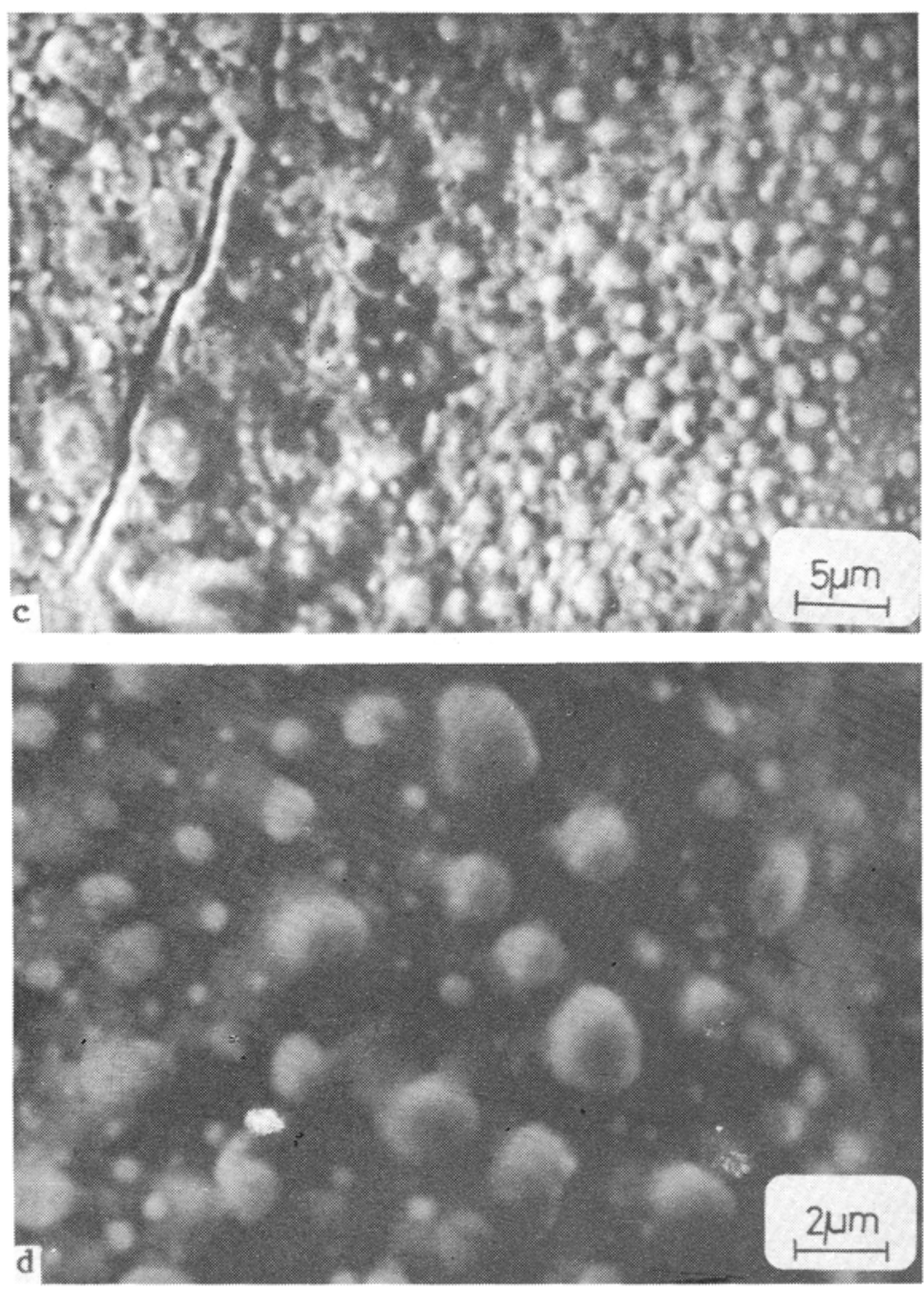

Figure 3. SEM micrographs showing the surface morphologies of the chromium-coated specimen laser-treated using Nd:YAG laser; (a) showing different tracks after laser treatment, (b) showing zone 1 with uniform $\mathrm{Fe}$ and $\mathrm{Cr}$ distribution, (c) and (d) showing zone 2 with chromia particles.

morphologies of the alloys formed with other sweep velocities. The optical micrographs of the cross-sections of the specimens for three different sweep velocities are shown in figure 8 . It shows that the laser-alloyed zone is very smooth, uniform and pore-free, compared to the as-coated specimens which were quite non-uniform and porous (figure 1).

The distribution of the alloying element in the laser alloying zone depends very much on the laser parameters and these are summarized in figure 9. It shows that the concentration of the chromium in the alloying zone decreases from about 


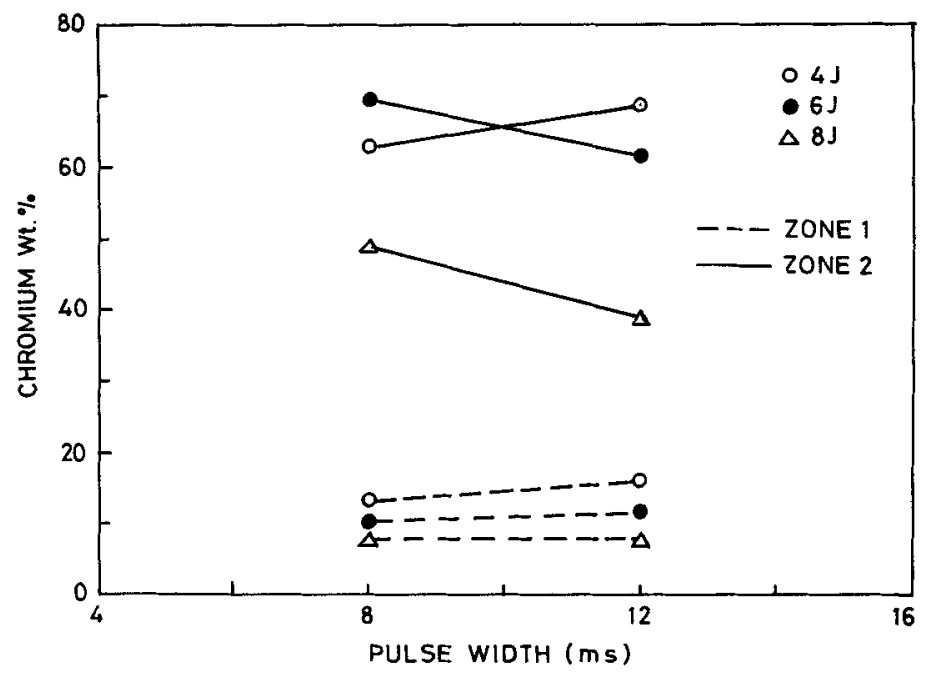

Figure 4. Effect of pulse width on the chromium distribution in two zones.

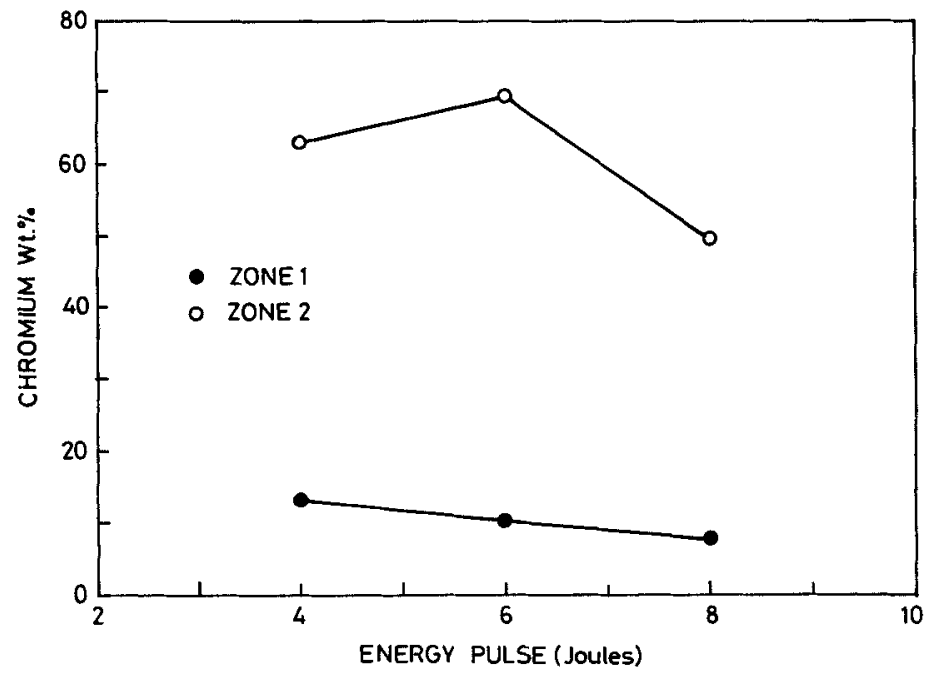

Figure 5. Effect of pulse energy on the distribution of chromium in two zones.

$22 \mathrm{wt} \%$ for LT7 to about $8 \mathrm{wt}^{\%} \%$ for LT9. It therefore implies that with increasing interaction time, i.e. with decreasing sweep velocity, the alloying element has enough time to diffuse into the matrix and therefore results in a thicker laser alloying zone as shown in figure 8 . The thickness of the alloy zone with laser parameters are given in table 2. The X-ray maps and X-ray line profiles through the cross-sections of the laser-dlloyed zone (LT9, LT8 and LT7), measured using an inclined WDS, are shown in figures 10,11 and 12 respectively. It appears that the distribution of chromium 

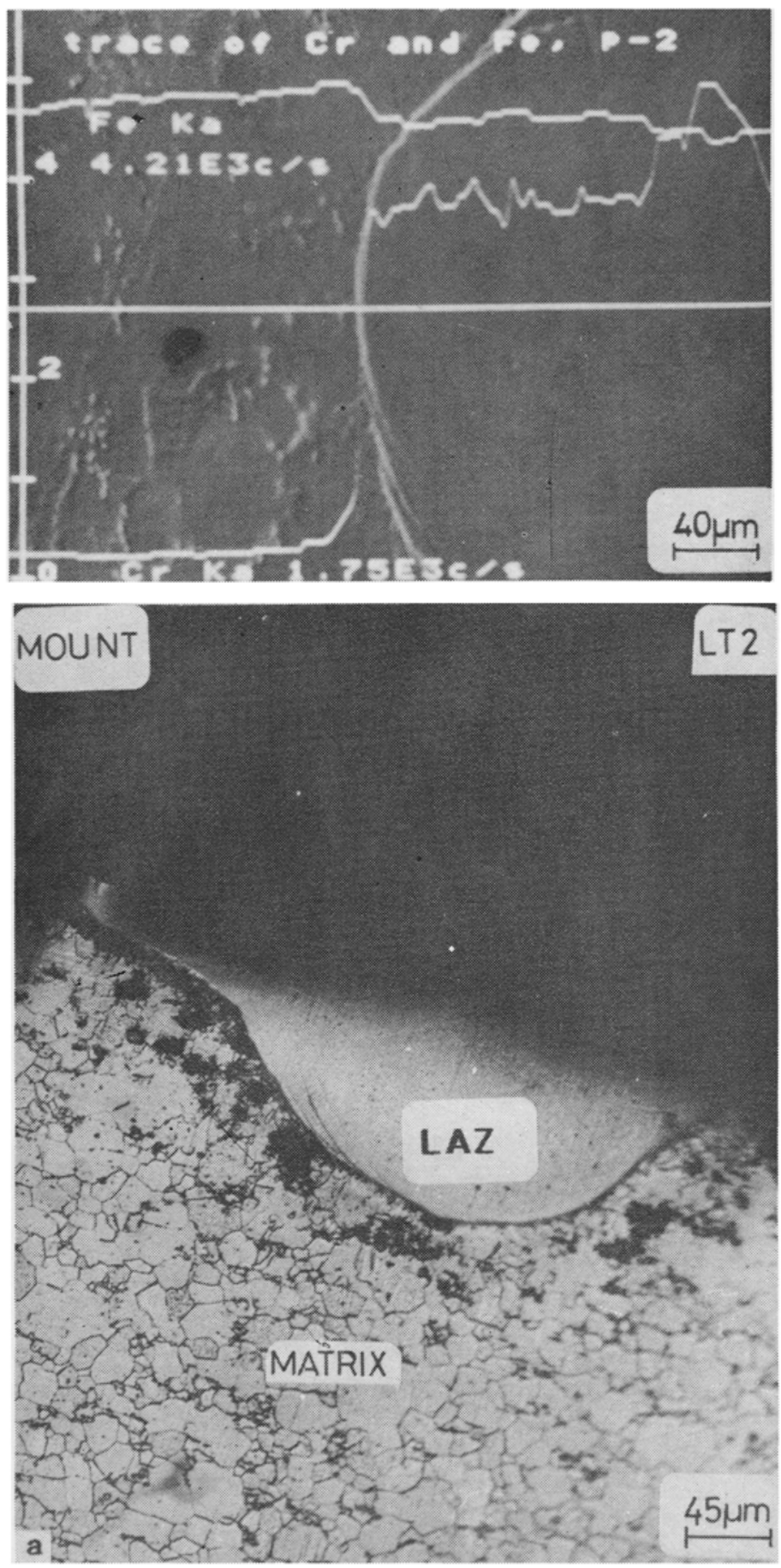

Figure 6a. 

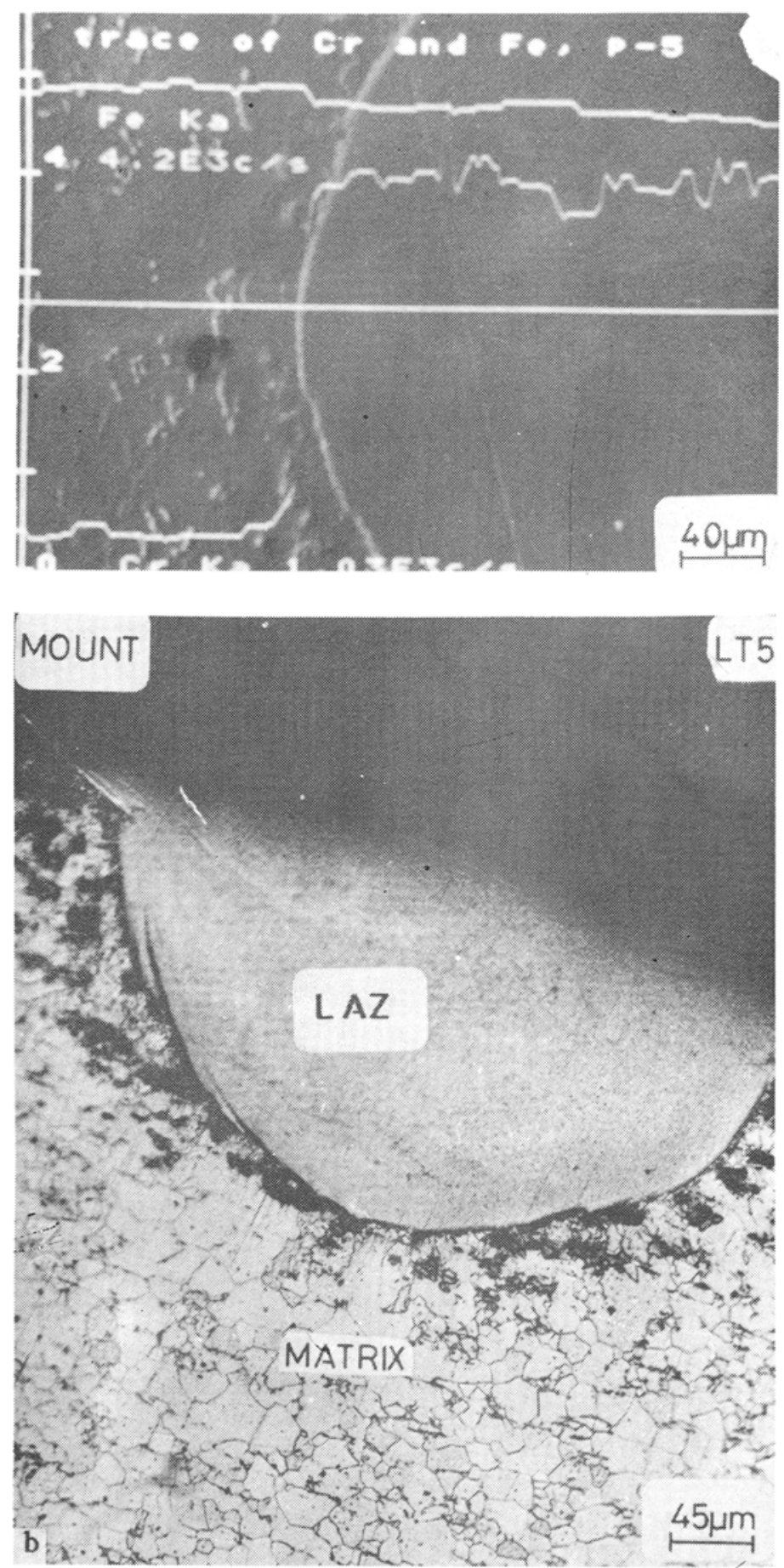

Figure 6. Optical micrographs showing the cross-sections of coated sample laser-treated using Nd:YAG laser with parameters (a) LT2 and (b) LT5, along with the SEM showing the chromium distribution using $\mathrm{X}$-ray line scan mode. 

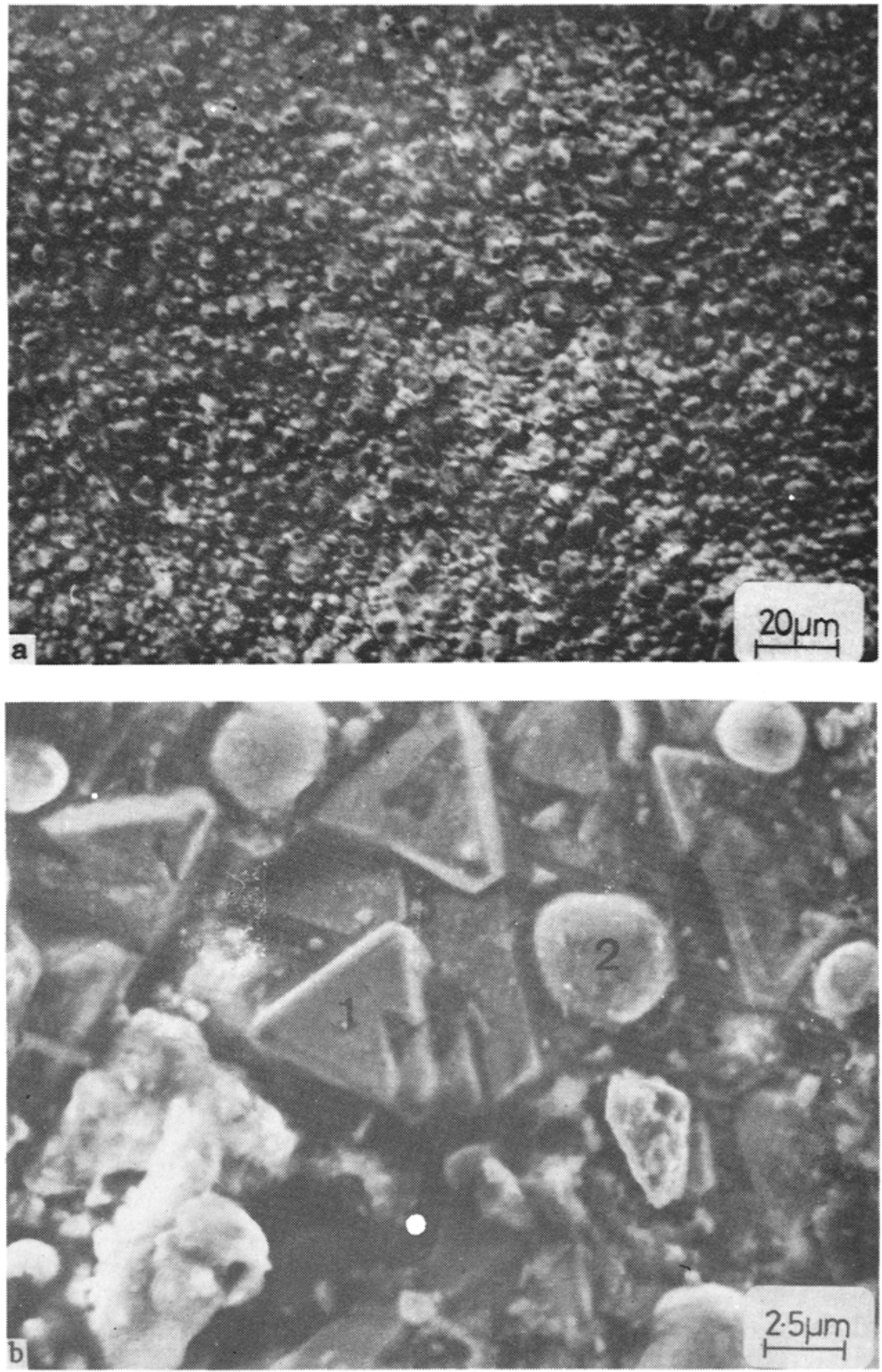

Figure 7. SEM micrographs showing (a) the morphology of the laser-treated specimen using $\mathrm{CO}_{2}$ laser and (b) showing fine structure at higher magnification.

in the laser alloying zone depends very much on the laser sweep velocity. This is clearly observed in the X-ray maps, which show the increases in the chromium distribution in the alloy zone when the laser sweep velocity increases, i.e. interaction time decreases. 

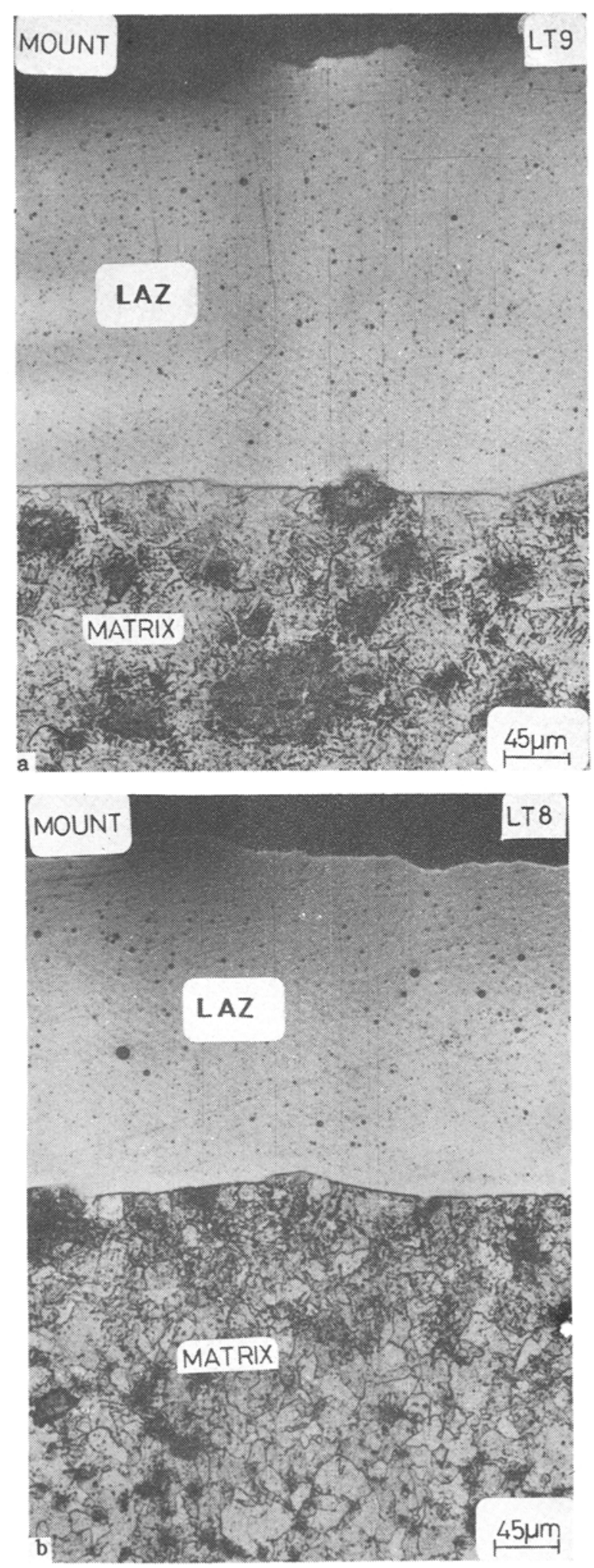

Figure 8. a-b. 


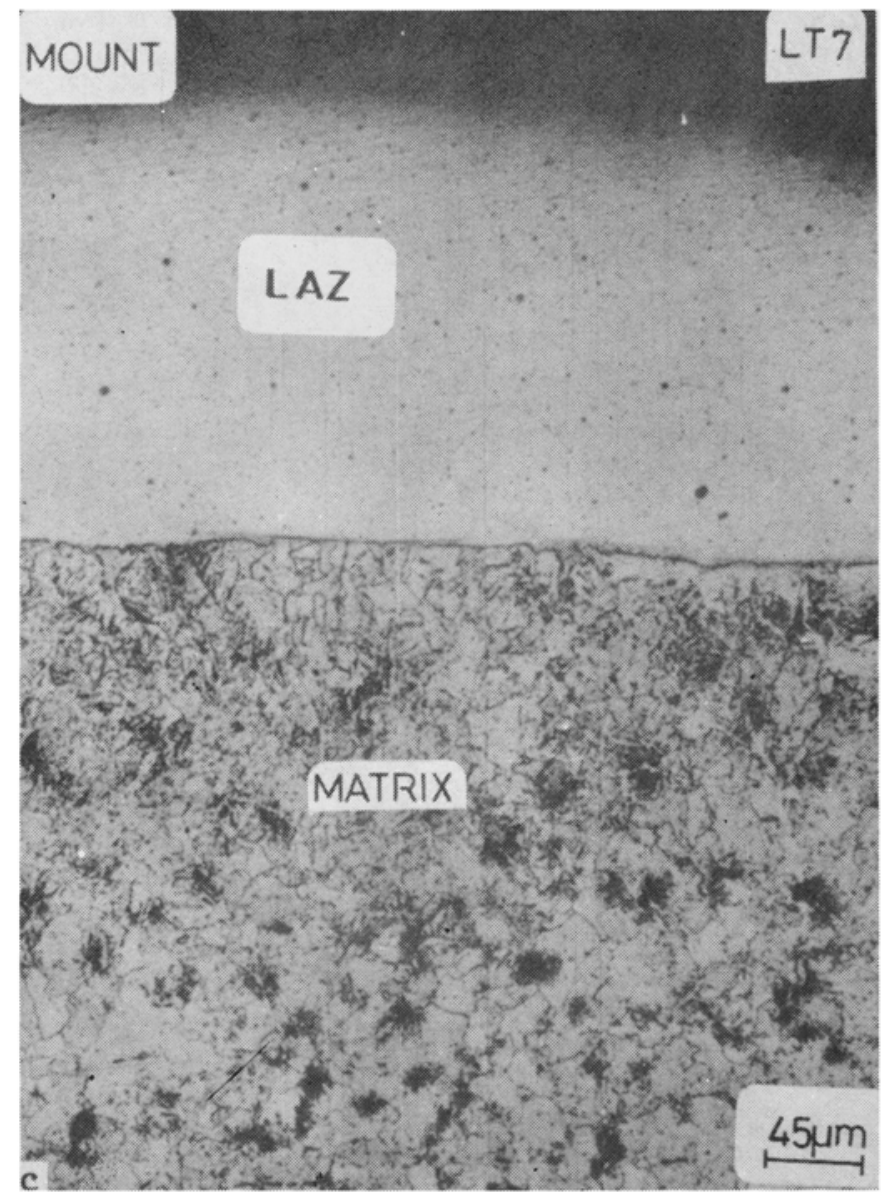

Figure 8. Optical micrographs showing the coating cross-section after laser treatment using $\mathrm{CO}_{2}$ laser with parameters (a) LT9, (b) LT8 and (c) LT7.

\subsection{Oxidation tests}

3.2a Nd:YAG laser-treated specimens: Oxidation results for the uncoated, plasmacoated and the Nd:YAG laser-treated specimens, with laser parameters LT2 and LT5, are shown in figure 13. It shows that the plasma-coated specimen has lower oxidation rate than the laser-treated specimens. This, though unexpected, can perhaps be attributed to the formation of an inhomogeneous laser-alloyed surface of chromium content much lower than that of the corresponding plasma-coated surface. Further the laser-treated specimen also cracked, especially in zone 2 , as shown in figure 3c.

3.2b $\mathrm{CO}_{2}$ laser-treated specimens: Figure 14 shows the oxidation result for uncoated, plasma-coated and $\mathrm{CO}_{2}$ laser-treated specimens. It is clearly evident from the figure that there is a considerable drop in the oxidation rate when mild steel is plasma-coated with chromium. The oxidation rate further drops after treatment with $\mathrm{CO}_{2}$ laser. However, there is little difference in the oxidation behaviour of the specimens treated with three 


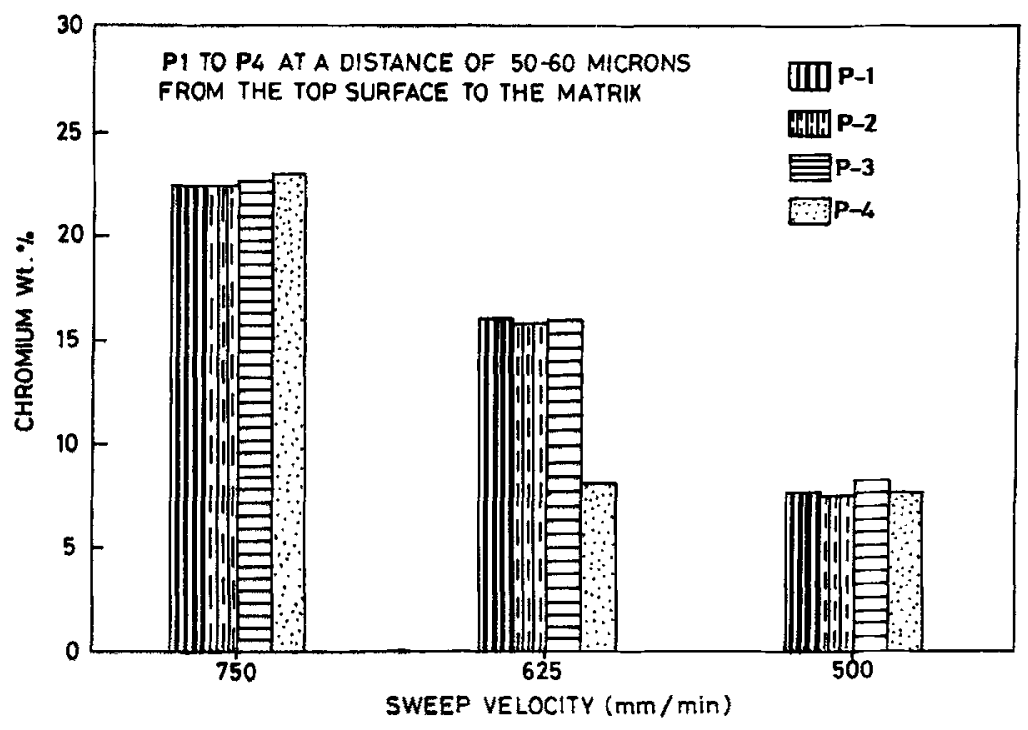

Figure 9. Concentration of chromium distributed in the coating after laser treatment with $\mathrm{CO}_{2}$ laser as a function of sweep velocity.

different laser parameters in spite of the fact that chromium level in the laser-alloyed zone varies from $22 \mathrm{wt} \%$ to about $8 \mathrm{wt} \%$. The main reason for improvement in oxidation resistance is therefore the formation of a uniform, pore-free surface alloy with better bonding.

\subsection{Corrosion tests}

Anodic polarization tests were carried out only on the samples treated with $\mathrm{CO}_{2}$ laser. Figure 15 shows the results for specimen $\mathrm{LT} 9$ in $1 \mathrm{~N} \mathrm{H}_{2} \mathrm{SO}_{4}$ solution. The polarization curves shown in the figure were obtained on the same sample after polishing about $40 \mu \mathrm{m}$ each time till the base metal was reached. As can be seen from the four curves a, b, c and d, all show passive behaviour with marginal change in the critical current density $\left(I_{\text {crit }}\right)$, increasing with depth, and also critical passive potential ( $\left.E_{\text {pass }}\right)$, increasing with depth, indicating that the corrosion behaviour deteriorates with subsequent removal of the laser-alloyed zone, perhaps due to continuous but slow

Table 3. Anodic polarization values for $\mathrm{CO}_{2}$ laser-treated specimen (sweep velocity of $500 \mathrm{~mm} / \mathrm{min}$ ).

\begin{tabular}{lccccc}
\hline Curve & $\begin{array}{c}E_{\text {Corr }} \\
(\mathrm{mV})\end{array}$ & $\begin{array}{c}I_{\text {Corr }} \\
\left(\mu \mathrm{A} / \mathrm{cm}^{2}\right)\end{array}$ & $\begin{array}{c}I_{\text {Critical }} \\
\left(\mathrm{mA} / \mathrm{cm}^{2}\right)\end{array}$ & $\begin{array}{c}E_{\text {Passive }} \\
(\mathrm{mV})\end{array}$ & $\begin{array}{c}I_{\mathrm{p}} \\
\left(\mu \mathrm{A} / \mathrm{cm}^{2}\right)\end{array}$ \\
\hline a & -482.00 & $1700 \cdot 00$ & 40.5 & $528-934$ & 134.9 \\
$\mathrm{~b}$ & -508.84 & 1692.72 & 61.9 & $526-932$ & 272.0 \\
c & -526.20 & 1504.30 & 73.3 & $536-940$ & 170.2 \\
d & -517.46 & 1781.36 & 106.0 & $528-952$ & 348.0 \\
\hline
\end{tabular}



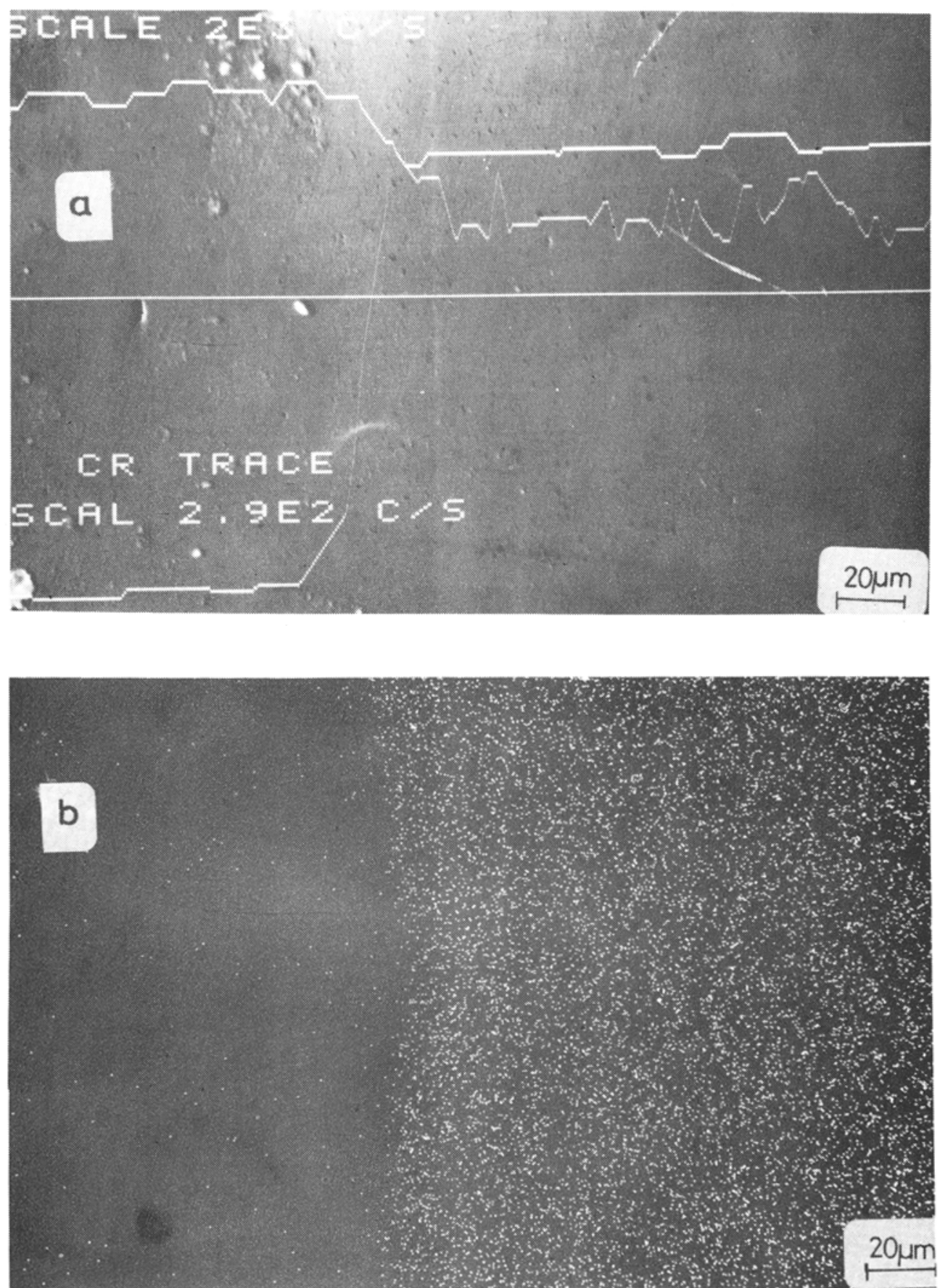

Figure 10. (a) SEM micrograph of the coating cross-section with $\mathrm{X}$-ray profile of $\mathrm{Cr}$ and (b) the X-ray point map showing Cr distribution in the LAZ for sample LT9. 

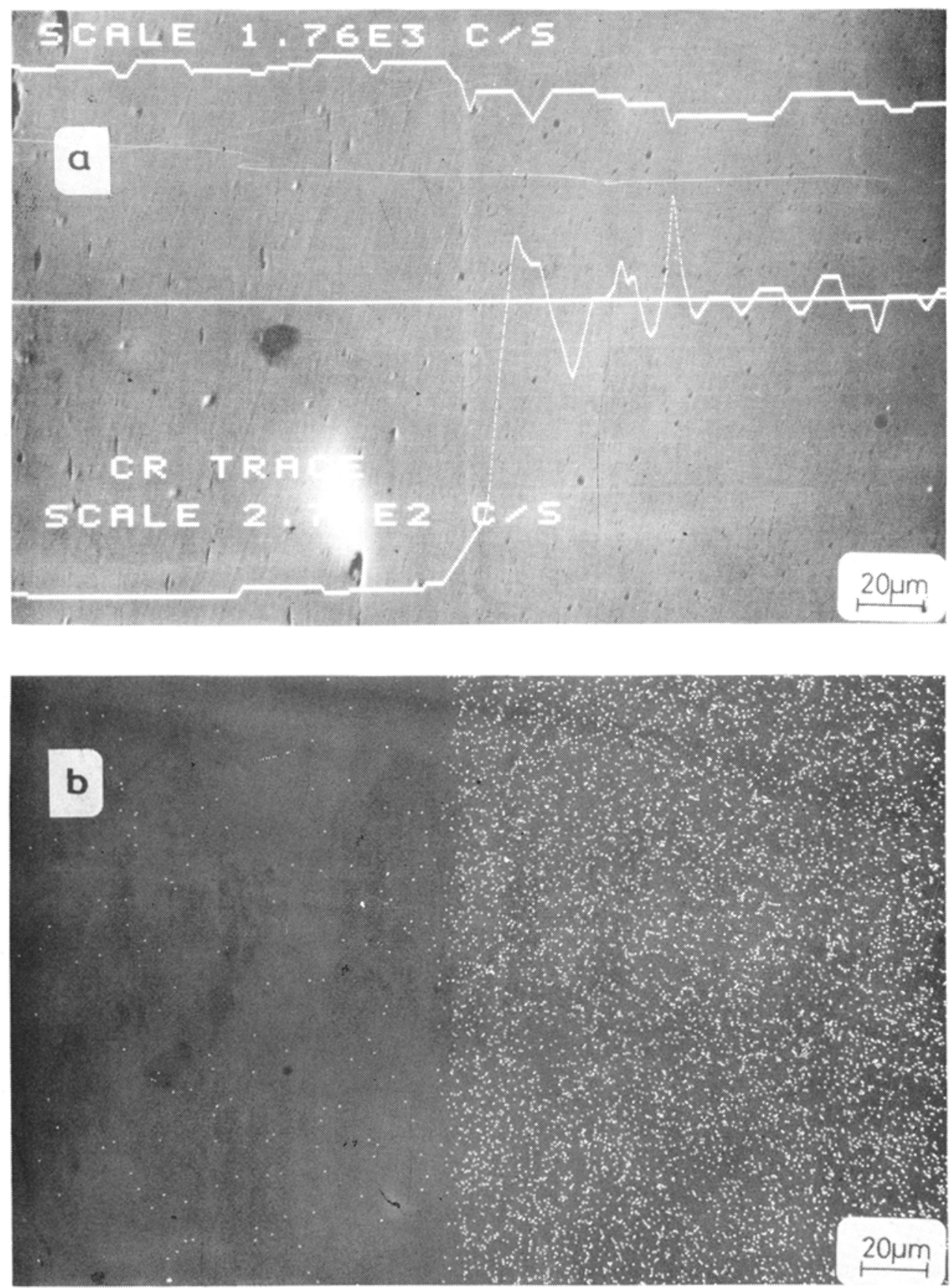

Figure 11. (a) SEM micrograph of the coating cross-section with $\mathrm{X}$-ray profile of $\mathrm{Cr}$ and (b) the X-ray point map showing Cr distribution in the LAZ for sample LT8. 

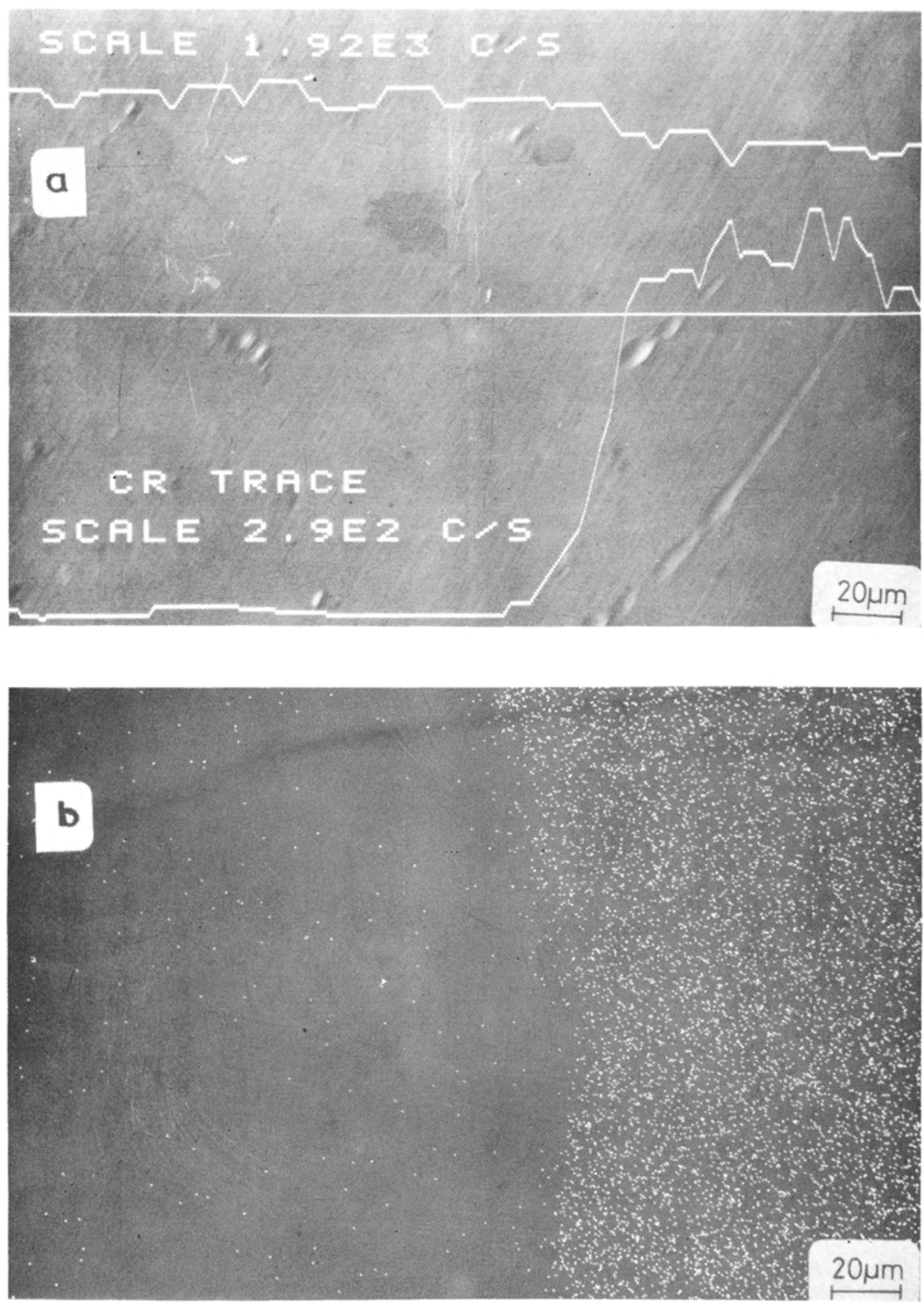

Figure 12. (a) SEM micrograph of the coating cross-section with X-ray profile of $\mathrm{Cr}$ and (b) the X-ray point map showing Cr distribution in the LAZ for sample LT7. 


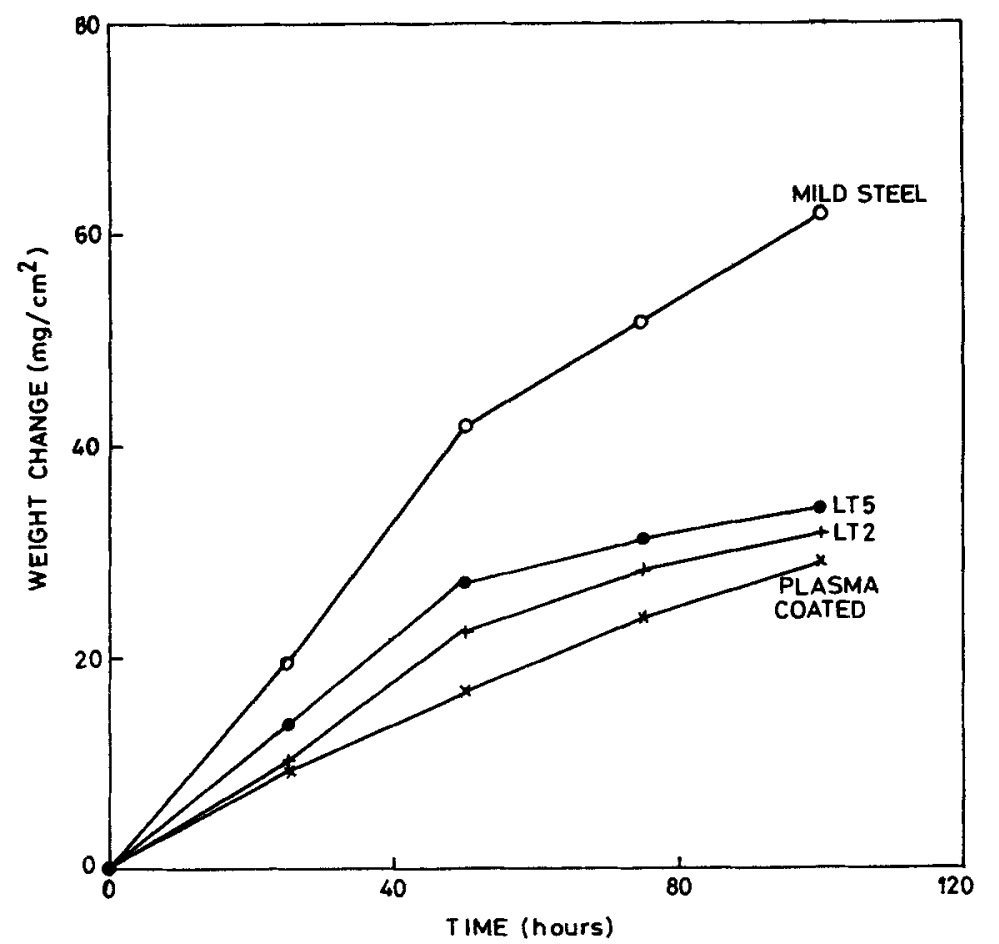

Figure 13. Linear plots of weight gain vs time for the oxidation of uncoated, plasma-coated and laser-treated (using ND:YAG laser) samples in air at $700^{\circ} \mathrm{C}$.

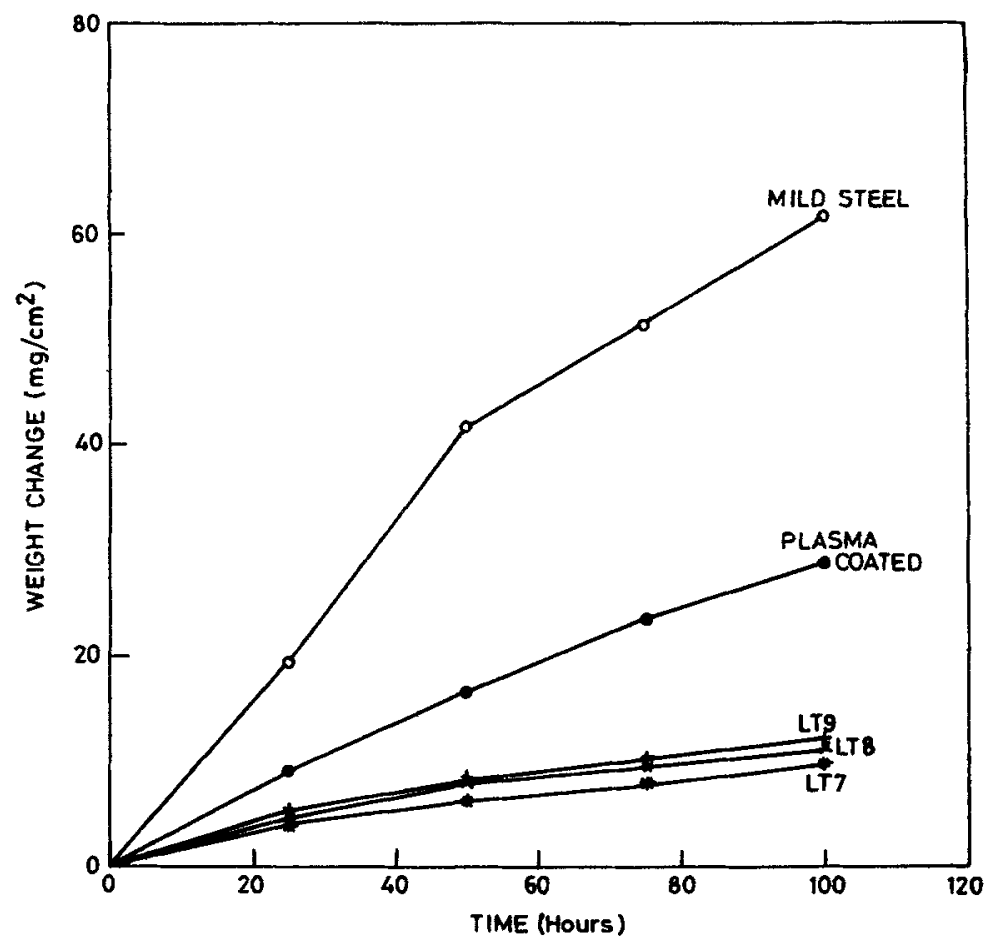

Figure 14. Linear plots of weight gain vs time for the oxidation of uncoated, plasma-coated and laser-treated (using $\mathrm{CO}_{2}$ laser) samples in air at $700^{\circ} \mathrm{C}$. 


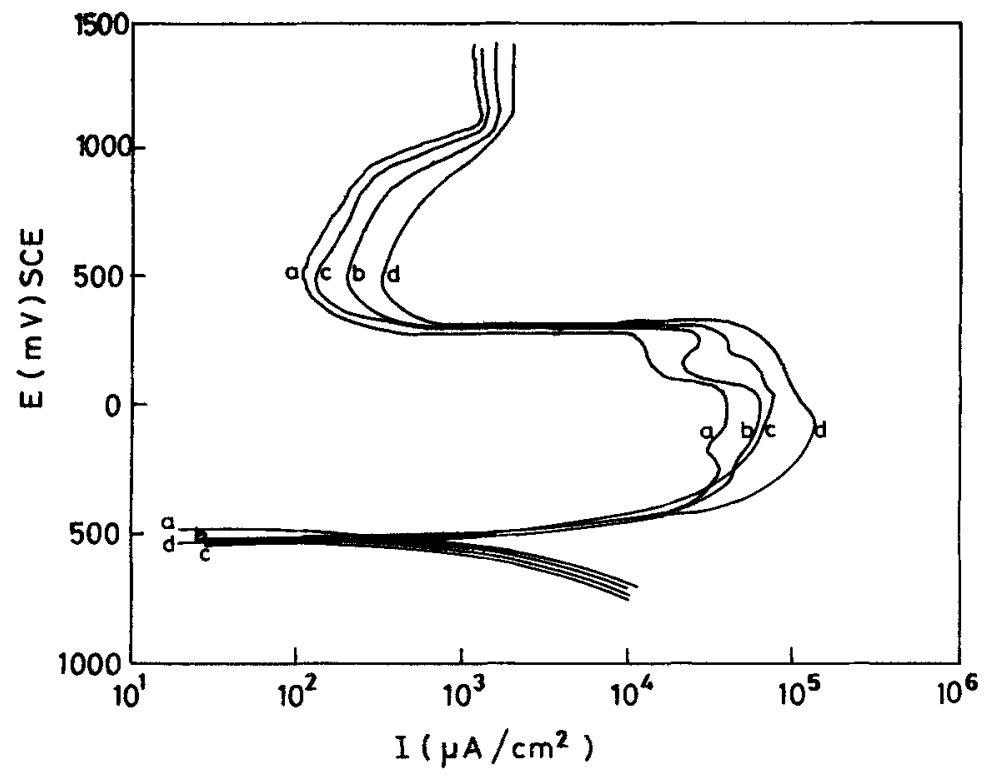

Figure 15. Anodic polarization curves for the sample LT9 in $1 \mathrm{~N} \mathrm{H}_{2} \mathrm{SO}_{4}$ at various depths from the coated surface.

decrease in the chromium concentration with depth. Table 3 lists variation of various corrosion parameters measured during the polarization test.

\section{Discussion}

The present results emphasize the characterization of the surface alloys formed as a result of laser treatment more than their oxidation or corrosion behaviour. Two different lasers were employed for laser treatment. A $300 \mathrm{~W} \mathrm{Nd}$ :YAG pulse laser is actually not a suitable tool for laser surface alloying. It is basically used for laser cutting and laser drilling. The two main limitations of this laser are: (i) it is a pulse laser as a result of which the power terminates after a fixed duration interrupting the melting process, (ii) its optics are not very good. It gives only a spot of size 1 to $2 \mathrm{~mm}$. This poses a great difficulty in getting a uniform laser surface-alloyed area. To get a minimum area of $10 \mathrm{~mm}^{2}$, for a reasonable corrosion and oxidation test, one has to use at least $60 \%$ overlapping from one track to the other. Thus there are more than 10,000 spots per $\mathrm{cm}^{2}$ with different history of cooling and heating. This results in two or more zones on the surface with heterogeneous composition and often intermediate cracks. Such a surface is not good for corrosion protection. That is why the oxidation results obtained on samples laser-alloyed using Nd:YAG laser show a bit higher oxidation rate in comparison to the corresponding plasmacoated surface, in spite of improvement in the surface roughness, density and bond strength. Nevertheless, detailed characterization of the surface-alloyed zone as a function of pulse width and pulse energy has shown how the composition of the laser-alloyed zone varies with these parameters. Lower pulse width with 
intermediate pulse energy of $6 \mathrm{~J}$ gives maximum concentration of chromium in the alloyed zone.

The results obtained with continuous $\mathrm{CO}_{2}$ laser are quite interesting and show that concentration of chromium in the laser-alloyed zone depends upon the chosen laser parameters. Because of the better optics, using a line focus mode, a uniform surface area with homogeneous composition was obtained with no cracks in the laser-alloyed zone. As confirmed in an earlier work by Khanna et al (1992), low interaction time retains maximum alloying element, lowest thickness of laser-alloyed zone, and hence better oxidation resistance. The observation of little difference in the oxidation rates of the three samples with different laser parameters (LT7, LT8 and LT9), having $\mathrm{Cr}$ concentration varying from $22 \mathrm{wt} \%$ to about $8 \mathrm{wt} \%$, is a bit surprising. However, considering $700^{\circ} \mathrm{C}$ a bit lower temperature and $100 \mathrm{~h}$ a bit short duration for oxidation test, the full beneficial effect of high $\mathrm{Cr}$ level cannot be fully judged. At this temperature, perhaps the three alloys have no significant difference in their oxide forming capability. Lower chromium in the alloyed zone for specimen treated for longer interaction time LT9 could be due to dilution in the larger alloyed zone and also some loss due to the evaporation of chromium during laser processing. These results are in conformity with those reported by Khanna et al (1992), in which they alloyed mild steel with stainless steel rather than pure chromium.

As far as aqueous corrosion results are concerned, the results are encouraging. Mild steel, which does not show any passivity in any acidic solution, is found to exhibit a good and stable passive zone after laser alloying. Although the values of $I_{\text {crit }}$ and $I_{\text {pass }}$ are far from those of 304 stainless steel, a stable passivity on mild steel confirms the surface having reasonable chromium level to achieve passivity and lower the corrosion rate.

\section{Conclusions}

From the present results, it can be concluded that for improving the corrosion and oxidation behaviour of a low-corrosion-resistant surface such as mild steel, laser surface alloying may be carried out using laser parameters which provide uniform, homogeneous laser-alloyed surface, with no cracks in the coating as well as in the underlying matrix. A continuous laser with high power and better optics such as line focus mode are required to achieve a homogeneous surface. Further, laser parameters which retain maximum concentration of the alloying components of the pre-coating should be chosen to enhance the protective properties of the alloyed zone. Corrosion and oxidation behaviour would therefore be enhanced as a result of higher concentration of these elements, for example $\mathrm{Cr}$ in the present case. Better coating methods, and perhaps a base with higher initial concentration of chromium, may also help to achieve higher $\mathrm{Cr}$ concentration on the New York.

\section{Acknowledgements}

The authors are grateful to Ms K Anuja, RSIC, IIT, Bombay, for helping in carrying out SEM/EDAX and WDS analysis and Mr Shreekumar, BARC, Bombay, for plasma spraying. This work is part of the sponsored project from the Department of Science and Technology, New Delhi. 


\section{References}

Arvidsson P E 1992 in Thermal spray coatings: Properties, processes and applications (ed.) Frank N Longo (Ohio: ASM International) p. 295

Chiba A Sato, Kawashima T, Asami K and Hashimoto K 1984 Corrosion Sci. 26311

Fairbanks J W and Hecht R J 1987 Mater. Sci. Eng. 88321

Gasser A, Kreutz E W, Leibrandt S and Wissenbach K 1988 Proc. 2nd European Conference on Laser Treatment of Materials, Bad Nauheim, Germany, (Dusseldorf: German Welding Society) p. 81

Honey F J, Kedward E C and Wride V 1986 J. Vac. Sci. Technol. A4 2593

Khanna A S, Singh Raman R K, Kreutz E W and Terrance A L E 1992 Corrosion Sci. 33949

Lugscheider E, Eschnauer H and Gruner H 1985 in Thermal spray coatings, New materials processing application (ed.) Frank N Longo (USA: ASM) p. 77

MacDowell L G 1992 Mater. Performance 3130

Parks Albert R 1985 in Thermal spray coatings: New materials, processing and application (ed.) Frank $\mathrm{N}$ Longo (USA: ASM) p. 65

Pujar M G, Dayal R K, Khanna A S and Kreutz E W 1993 J. Mater. Sci. 283089

Roy S K, Fasasi A, Pons M, Galerrie A and Caillet M 1993 J. Physique IV 3625

Steen W M and Watkins K G 1993 J. Physique IV 3581

Stott F H, Bartlett P K N and Wood G C 1987 Mater. Sci. Eng. 88163 